\title{
Consent in paediatrics: a complex teaching assignment
}

\author{
Valerie J Grant Auckland School of Medicine, Auckland, New Zealand
}

\section{Author's abstract}

The topic of consent in paediatrics is made more difficult, and at the same time more interesting, by the complexity of the issues involved and the consequent diversity of viewpoints. In a teaching session for senior medical students on consent in paediatrics it proved necessary to reinstate previous learning from a range of disciplines. Philosophical medical ethics, developmental psychology, communication skills and the appropriate legal definitions all contributed to a proper understanding of the cases presented. The two most important additional components appeared to be a) a basic knowledge of cognitive development and how to apply it, and b) an awareness of the need to balance an individual child's rights or best interests, with those of the family unit, as well as the wider society.

\section{Introduction}

When paediatricians first approached the Interdisciplinary Teaching Committee on Medical Ethics about the possibility of 'doing something in ethics', the teaching task looked reasonably straightforward. Several factors contributed to this illusion. First, in the context of the overall programme at the Auckland Medical School, it was readily agreed that the most pressing issue in paediatrics was consent. Secondly, a number of outside constraints and other considerations dictated the form of the teaching session. It was to be a whole-class session, no more than two hours. Thirdly, a number of paediatricians with different areas of expertise offered to contribute by describing clinical cases in which they had experienced ethical dilemmas. And lastly, as on previous occasions a philosopher was to be present to help clarify issues and to present a summary at the end. Since the session was similar to others held at this school (1) problems were not expected.

However, although the session ran smoothly enough, there was a growing sense of unease amongst some participants. For others, difficulties did not

\section{Key words}

Medical ethics teaching; consent; paediatrics. become apparent until a later review of the teaching in this area. The problem was that when it came to a consideration of the issue of consent, the child patients had been viewed as a homogeneous group, whether they were four or fourteen years old. Very little attention had been paid to the age or developmental stage of the child, let alone the effect this had on the potential for the child to be included in the decisionmaking process.

A second difficulty was the lack of clarity surrounding the ethical issues which parents might take into consideration in coming to an understanding of their own preferences. Some participating clinicians assumed that parents would focus on the child's rights, or on the best interests of the child, and others assumed they would be deciding in the best interests of the family unit. In this area differing attitudes among students, paediatricians and moral philosophers were not made plain the first time we ran this session.

\section{A second try - the 1990 version}

The following year the session was presented in a similar format, but much more attention was paid to the above issues. The session was organised by a group of teachers, one of whom later acted as chairperson. It was run as informally as possible given the constraints of time (two hours), setting (a large raked lecture theatre) and number of participants (110 students, four paediatricians, a philosopher and the chairperson).

To ensure that all the relevant dimensions of problems were considered, a period of about 20 minutes was spent at the beginning of the symposium reinstating in summary form previously learned material from related areas.

These interconnected topics included theories in philosophical medical ethics especially those which underpin the worldwide push towards increased patient participation in medical decision-making; developmental psychology, and in particular, normal cognitive development; a knowledge of the legal view of relationships between medical practitioner, child patient and parents or guardians and finally a reminder of knowledge and techniques in communication skills. This last topic included a brief review of the skills required to facilitate the processes whereby distressed people may come to an understanding of their own 
preferences and an ability to provide the psychological environment in which this may occur.

For students at the Auckland School of Medicine most of these related topics had been covered in former years. Students had had a two-term course in developmental psychology in their second year. They had had programmes in communication skills and in philosophical medical ethics spanning four years. The only new material was that which involved a description of the fiduciary relationship between parents and children in the legal sense, and this input was minimal. The main purpose of this part of the session then was to reinstate previous learning and to demonstrate how a number of different topics and skills could be brought together to form the basis of expertise relevant to consent in paediatrics.

To facilitate discussion and to ensure that students had before them reminders of all the relevant areas of knowledge, full use was made of the lecture theatre's three large blackboards. Before either students or paediatricians came into the session, subject headings were written up (see Table 1). On arrival, everyone's attention was drawn to the material on the blackboards and there was some amplification of it, giving students a chance to review and remember what had been learned on previous occasions. The presence of this material might also have served as a useful background for contributing clinicians who would not necessarily be aware of new content in contemporary medical training courses.

As can be seen from the following case descriptions, the complexity of the issues and the diversity of opinions on each, increased according to the age of the child at the centre of each case. Everyone present was entitled to contribute to the discussion and did so either on their own initiative or in response to questions from others. Questions and comments were kept succinct in order to allow as many viewpoints as possible to be heard. One of the advantages of sessions like these is that all participants have something that only they can contribute. The philosophers and the clinicians each have their specialist expertise. The students, at the beginning of their fifth year of training, are on the threshold of putting it all together. Time constraints at first appeared regrettable, but it is now known that discussions continued long after the formal session was over.

\section{The cases}

The main part of the session consisted of the presentation of four cases around the general theme of consent in paediatrics. Each was presented by a different clinician. The first three cases were specially chosen to represent children at different stages of cognitive development. The fourth presentation posed a problem related to non-therapeutic research with infants. To facilitate consideration of the role of cognitive development, the clinical cases were taken in order, from pre-operational child to adolescent at the stage of formal operations.

\section{CASE 1 - THE PRE-OPERATIONAL CHILD}

The first case concerned a four-year-old boy and the dilemma arising from having to choose between conservative and aggressive treatment of his terminal condition. Discussion of this problem focused mainly on the responsibilities of paediatrician and parents, the need for the highest possible level of skill in communication, an appeal to the virtues of courage and compassion, a passing reference to allocation of resources issues, as well as, finally, a recommendation about the most appropriate course of treatment. In this case there was no disagreement about whether or not the child should be included in the decision-making process. On the other hand, central to the major problem was a consideration of the needs of a younger sibling, as well as the best interests of the family as a unit.

\section{CASE 2 - THE CONCRETE OPERATIONAL CHILD}

The next case involved a child in the middle of the concrete-operational period of cognitive development. The second paediatrician described how his patient, a nine-year-old girl was admitted with 55 per cent of her body surface area burned after her nightdress caught fire from a portable gas heater in her bedroom. Treatment of her full thickness burns proceeded according to plan for the first three days. At that time however, a fluid loss/balance problem arose and it waon decided that temporary burn-cover could be achieved only by the use of modified pig skin. The paediatrician, at that time a more junior practitioner, had an excellent relationship with his young patient. However, when told that her treatment was to involve pig skin she adamantly refused, saying she would rather die than have skin made from a pig.

During the class discussion of this case, several creative suggestions were offered about the ways in which the proposed treatment might be described to a child of nine years. The most important issue however was that concerning the rights of a child in this age group (7-11 years) to give or withhold consent to treatment. Reminders about cognitive development clarified the situation. Concrete-operational children cannot handle conflicting viewpoints, and cannot argue from contrary-to-fact hypotheses. In this age group, children tend to perceive things as either totally bad or as totally good, relying in this regard on parents and teachers as authority figures, whose views are inviolable. Thus it was not appropriate to invite such a child into a discussion of treatment alternatives. An attempt to do so would almost certainly have resulted in bewilderment, anxiety and extreme responses. What the child needed was a united and confident approach from caregiversand parents.

Therefore the combined effect of a knowledge of cognitive development, the principles of clinical practice, communication skills and medical ethics was to arrange for explanations to be given and permission to be sought from the parents before an approach was 


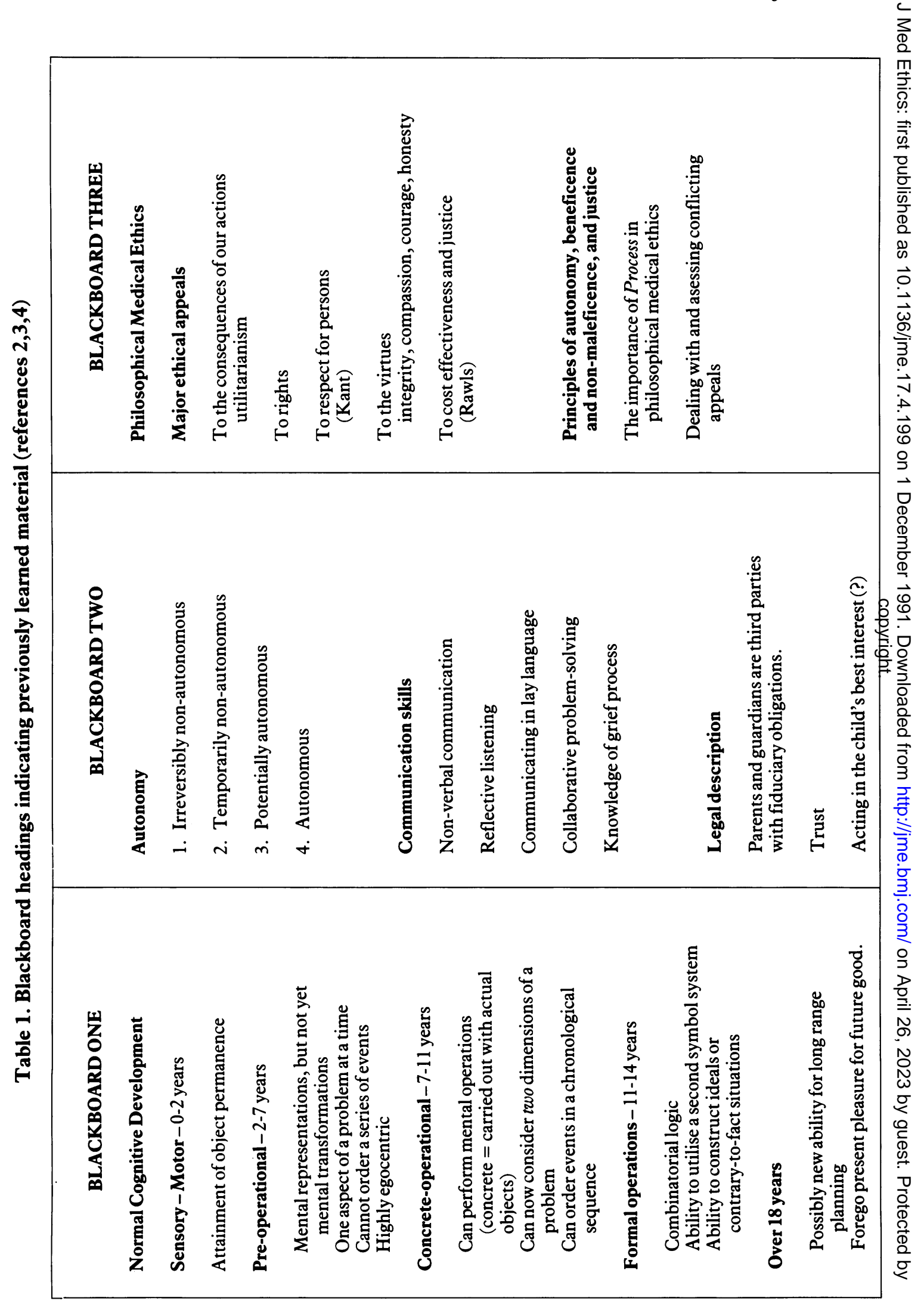


made to the child. If the parents were satisfied that the proposals were in the best interests of their child, then the ideal would probably have been for parents and paediatrician together to inform the child about the good plans they had for her. Any leaking of anxiety by a parent would almost certainly be communicated to the child. Because of this, extra time taken to gain the full approval of the parents would be of direct benefit to the patient. Where all members of the health team recognised this, parents and children would be more likely to receive optimum care.

\section{CASE 3 - AN ADOLESCENT AT THE STAGE OF FORMAL OPERATIONS}

The third case was presented by a child psychiatrist and involved dilemmas of confidentiality and patient autonomy as well as consent. Having obtained parental permission to do so, a teacher referred her 4th form pupil to a child and adolescent psychiatric clinic, saying she was concerned about frequent absences from school. In addition, the girl had recently arrived in class drunk and distressed. On interview she was found to be tall and well-developed, looking older than her 14 years. She told the psychiatrist that she had been drinking heavily during the day, had been taking a variety of drugs which she obtained through night clubs, and that she had been prostituting herself to pay for them. She suspected she might be pregnant and requested an AIDS test. She said she had been depressed lately. She was indifferent about receiving 'help' but insisted her parents not be involved or contacted.

Discussion of this case centred on the girl's right to privacy and the manner in which ethical demands for confidentiality and respect for patient autonomy could be reconciled with proper consent to treatment. Some argued that since the parents had clearly failed in their responsibilities towards their daughter, they had also automatically forfeited their right to be informed about her, whether or not consent was required. Others thought they should be made to take an interest in her, or at least help to provide appropriate parental guidance.

More importantly, it was noted that in terms of cognitive development this young person now had at least the potential to be able to weigh up the advantages and disadvantages of different suggestions concerning her treatment and lifestyle options. It was also noted that although an adolescent might be capable of formal thought (ie the ability to perform complex mental operations such as hypothetical-deductive thinking, second order operations, and the ability to construct ideals), this would be a recent acquisition which would take years of experience to reach anywhere near its potential.

This adolescent had had little opportunity to make use of her new potential for formal thought in either of the settings available to her more fortunate peers. She had been denied the usual opportunities to debate the familiar household rules with parents, or to discuss these with contemporaries. In addition to clinical care, she needed the opportunity to begin to explore her own views with a non-judgemental listener. In fact, the presenting psychiatrist said she had been able to reach her patient by discussing with her what she would recommend for a (hypothetical) friend in a similar situation, thus making creative use of the adolescent's newly acquired potential for arguing from contrary-tofact hypotheses. By interacting with her patient at a cognitively appropriate level, the psychiatrist made it possible for the young woman later to accept further adult support.

\section{CASE 4 - THE USE OF INFANTS IN NON-THERAPEUTIC} RESEARCH

In this case the presenting paediatrician had taken part in the deliberations of the research committee to which the proposal had been submitted for ethical approval. The research involved the monitoring of breathing, muscle tone and Electroencephalograph (EEG) recordings of normal infants at fortnightly intervals from age four weeks to 26 weeks. This was to be a study which might elucidate the boundaries between normal and abnormal development in some specific areas thought to be involved in sudden infant death syndrome (cot death), a distressingly frequent occurrence in New Zealand at the present time.

Discussion of this case included the usual points that parents must be invited to take part, that they must be assured that refusal would not compromise future care in any way, that the parents must be fully informed about what the research would consist of and the reasons why it was being done, and that the parents must have the right to withdraw from the study at any time without giving a reason.

The key issue however was the risk-benefit ratio. Although the research was, strictly speaking, noninvasive, it did involve attaching electrodes to the skin at various points, including the upper eyelid. Some argued that it was the paediatrician's responsibility to put the case for the research project in a positive way, emphasising its possible future benefits to society as a whole. It was then up to the parents to give or withhold consent on behalf of the infant, taking into consideration any factors they themselves thought relevant, such as inconvenience to the caregiver and possible distress to the child. In addition, parents should decide whether or not they would be proud to tell their child later that he or she had taken part in an altruistic endeavour for the benefit of future at-risk infants.

\section{Discussion}

Whilst ethical dilemmas involving consent in paediatrics may not be intrinsically any more difficult than those in other areas of consent in medicine, it is probably true to say that they are made more complex, and thus potentially more contentious, by two further issues. First there seem to be misunderstandings about the capacity of a child of any particular age to take part 
in the decision-making process. Secondly, where a parent, guardian or other proxy must make the decision, should this be made on the basis of children's rights, the best interests of the child or the best interests of the family unit?

\section{THE CHILD'S STAGE OF COGNITIVE DEVELOPMENT}

To a developmental psychologist, the questions about the extent to which the child should or should not take part in the decision-making process, must be preceded in the first instance by a consideration of the question, to what extent is a child (of a particular age) able to take part in such a discussion.

The idea that a child may or may not be able to take part, according to the stage of cognitive development (not related to intelligence), appears not surprisingly, to be ill-understood by many authors. (Even those that acknowledge there is such a thing as cognitive development are sometimes so uneasy with the concept that they hesitate to make use of it for fear of being accused of unethical behaviour by children's rights activists.)

For example, Redmon (5) says: 'By "children" I mean those individuals whom we think, by reason of their lack of years, are unable to make rational decisions on those matters which affect their long or short-term interest ... I do not intend to suggest when this occurs ...' '. And in his discussion of the relative incompetency of children to give consent, Brody (6) writes that 'Children often lack the reasoning ability to calculate which options would maximise the expected outcome'. If by 'often' he means all children under the age of 11 years, most developmental psychologists would agree with him. If however, he is referring to differences in education, in intelligence or any other variable, then most people familiar with normal cognitive development would disagree with him on the grounds that more precision would normally be expected in such a statement.

Similarly, Beauchamp and Childress (7), discussing subject selection in research on children, say: 'It seems morally relevant to distinguish within the class of children between older and younger children - or, better, between children who comprehend and report their feelings with clarity and those who have limited capacity to comprehend and describe'. In both instances, although the authors are making important distinctions, the critical point, namely the stage of cognitive development, has been omitted from consideration.

Since cognitive development is not widely understood, it may be necessary to include a developmental psychologist in any team considering the appropriate level of participation in consent issues involving children. This would be particularly important in deciding who should give consent in research settings.

Tranoy (8) discusses the recommendations of a research ethics committee faced with a difficult task. On the one hand they were confronted with a law which does not permit parents to consent to the participation of their children in non-therapeutic trials. On the other hand, they had to make a decision concerning a non-therapeutic trial of a vaccine designed to counter a form of contagious meningitis particularly prevalent in Norway. They decided that the law led to an ethically unacceptable situation, namely that a potentially life-saving vaccine could never be made available because no one was legally permitted to consent to testing it.

In recommending by-passing the law, they stipulated the conditions under which the vaccine might be tested. Tranoy writes: 'Parental consent would still be a necessary condition. The youth and children should be informed and parents ought not to give consent if the children protested' (9). But as in case 2 , the concrete operational child, the process by which children under 11 years of age are likely to arrive at agreement or disagreement is almost entirely related to those messages they have picked up from the subtext of their parents' invitations.

\section{WHOSE BEST INTERESTS?}

In each instance during this teaching symposium, once the question of who should be involved in the decisionmaking process was decided, the question of competing interests became the most important issue@ When parents, guardians or members of the medicat team find themselves having to make proxy decisions. in cases involving children, should they give more weight to the child patient's best interests, to the best interests of the family unit or to the best interests of society?

In considering the relative merits of differing viewpoints O'Neil (10) discusses problems of proxy consent in a variety of patient categories including one directly relevant to children, described as those who 'are and always have been incompetent but who have the capacity for competency in the future'.

According to O'Neil, some authors have suggested that the rule of 'substituted judgement' should be applied to decisions made on behalf of child patients. This means that the proxy decision should be made in response to the question, which treatment would the patient choose if competent? Other authors have suggested that choices should be made on the basis of the 'best interests' test; that is, which treatment would benefit the patient? O'Neil argues that neither of these is completely satisfactory. He suggests that a better formulation would be: 'What would the incompetent patient choose if his or her choice were rational?', thus paving the way for the widest possible consideration of every case. O'Neil agrees that family members should have the right to answer that question on behalf of the patient.

It came as a surprise to some staff members taking part in the symposium to find afterwards that of the four cases presented, the child's best interests were directly paramount in only one instance, that of the nine-year-old girl (case 2). In all the other cases, the 
child's best interests were taken to be equal or subordinate to considerations from a wider context. In the case of the four-year-old boy (case 1), the interests of the family, and in particular a younger sibling, were of considerable importance in coming to a decision to give palliative care only. In the case of the teenage girl whose family had ceased to care for her (case 3), the interests of the young woman were considered in conjunction with those of society as a whole; and in the research case, the interests of society were given the greatest emphasis.

As Schoeman (11) points out, it can be argued, as it was in this session, that parents may be 'permitted to compromise the child's interests for ends related to ... familial goals and purposes'. In addition, Schoeman argues, in the context of medical decision-making with respect to children, we should 'broaden our understanding of the context of the decision, and acknowledge that interests are at stake in addition to those of promoting the child's best interest'.

In arriving at the decisions described above, a variety of viewpoints was heard from staff and students. This diversity of opinion arose as much from differing individual perspectives as from different academic orientations. For example, some clinicians (and students) saw it as their primary clinical duty to advise and act in their patient's best interest. 'Who will be advocate for the child, and only the child, if we are not,' they asked. Other clinicians (and students), although acknowledging this as a very important duty, saw it as equally important to take into consideration familial and societal goals. As in previous sessions, the superior knowledge of the students in some theoretical areas was counterbalanced by the experience and knowledge of the paediatricians about the constraints and problems encountered in clinical settings.

The planning and organisation of new teaching sessions in medical ethics has proved unexpectedly stimulating for the staff members involved. In clarifying issues for students, inconsistencies or problems emerge which were unthought of before being exposed to the rigorous atmosphere of the lecture theatre.

Valerie $f$ Grant, $M A, P h D$, is Senior Tutor in Beihavioural Science and Cihairman of tihe Interdisciplinary Teacihing Committee in Medical Etihics, Auckland Scihool of Medicine, Auckland, New Zealand.

\section{References}

(1) Grant V J. Advanced medical ethics symposia for fifthyear students. Fournal of medical ethics 1989; 15: 200 202.

(2) Elkind D. Children and adolescents: Interpretive essays on Fean Piaget. New York: Oxford University Press, 1974.

(3) Sund R B. Piaget for educators. Columbus, Ohio: Bell and Howell, 1976.

(4) Mason J K, McCall Smith R A. Law and medical ethics. London: Butterworth, 1983.

(5) Redmon R B. How children can be respected as 'ends' yet still be used as subjects in non-therapeutic research. Fournal of medical ethics 1986; 12: 77-82.

(6) Brody B. Life and death decision making. New York: Oxford University Press, 1988: 103.

(7) Beauchamp T L, Childress J F. Principles of biomedical ethics. New York: Oxford University Press, 1989: 263.

(8) Tranoy K E. Research in bioethics. Bulletin of medical ethics 1990 ; 55: 18-22.

(9) See reference (8): 20.

(10) O'Neil R. Determining proxy consent. Fournal of medicine and philosophy 1983; 8: 389-403.

(11) Schoeman F. Parental discretion and children's rights: background and implications for medical decisionmaking. Fournal of medicine and philosophy 1985; 10:4561.

\section{Continued from page 195}

used on but a small proportion of the population, and replacing them with a code of practice which would apply much more broadly to all disabled and elderly people who want to stay at home and who are unwilling to enter hospital.

\section{f A Muir Gray, MD, is a Consultant in Public Health}

Medicine at the Radcliffe Infirmary, Oxford.

\section{Reference}

(1) Greaves D A. Can compulsory removal ever be justified for adults who are mentally competent? Fournal of medical ethics 1991; 17: 189-194. 